\title{
Impact of long-acting injectable antipsychotics on medication adherence and clinical, functional, and economic outcomes of schizophrenia
}

This article was published in the following Dove Press journal:

Patient Preference and Adherence

12 November 2013

Number of times this article has been viewed

\author{
Gabriel Kaplan ${ }^{1,2}$ \\ Julio Casoy ${ }^{3}$ \\ Jacqueline Zummo ${ }^{3}$
}

'Behavioral Health Services, Bergen Regional Medical Center, Paramus, NJ, USA; ${ }^{2}$ Department of Psychiatry, Rutgers New Jersey Medical School, Newark, NJ, USA; ${ }^{3}$ Medical Affairs, Alkermes, Inc., Waltham, MA, USA

Correspondence: Gabriel Kaplan 535 Morris Avenue, Springfield, NJ 0708I, USA

Tel +l 9733761020

Email drgkaplan@gmail.com

\begin{abstract}
Schizophrenia is a debilitating chronic disease that requires lifelong medical care and supervision. Even with treatment, the majority of patients relapse within 5 years, and suicide may occur in up to $10 \%$ of patients. Poor adherence to oral antipsychotics is the most common cause of relapse. The discontinuation rate for oral antipsychotics in schizophrenia ranges from $26 \%$ to $44 \%$, and as many as two-thirds of patients are at least partially nonadherent, resulting in increased risk of hospitalization. A very helpful approach to improve adherence in schizophrenia is the use of long-acting injectable (LAI) antipsychotics, although only a minority of patients receive these. Reasons for underutilization may include negative attitudes, perceptions, and beliefs of both patients and health care professionals. Research shows, however, significant improvements in adherence with LAIs compared with oral drugs, and this is accompanied by lower rates of discontinuation, relapse, and hospitalization. In addition, LAIs are associated with better functioning, quality of life, and patient satisfaction. A need exists to encourage broader LAI use, especially among patients with a history of nonadherence with oral antipsychotics. This paper reviews the impact of nonadherence with antipsychotic drug therapy overall, as well as specific outcomes of the schizophrenia patient, and highlights the potential benefits of LAIs.
\end{abstract}

Keywords: adherence, long-acting injectable, antipsychotics, schizophrenia, discontinuation, relapse

\section{Introduction}

Schizophrenia is a chronic, neurodevelopmental disorder also involving neurodegenerative mechanisms, characterized by alternating periods of full or partial remission and frequent relapses (return of symptoms after at least partial recovery). ${ }^{1}$ Evidence suggests that with each relapse, the time required to reach remission is extended. ${ }^{2,3}$ Much of the clinical and psychosocial deterioration that is typical of schizophrenia occurs within the first 5 years following the onset of the disease. ${ }^{4}$ Despite the availability of effective typical and atypical antipsychotic drugs for acute and chronic treatment of schizophrenia, $80 \%$ of patients relapse within 5 years, and suicide occurs in up to $10 \% .^{5,6}$ The relapse rate in first-episode schizophrenia is $16 \%$ during the first year of illness, but rises to $>50 \%$ at 2 years and $>70 \%$ at 5 years. ${ }^{6,7}$ The most common cause of relapse in treated schizophrenia is poor adherence to oral medication, where adherence is generally defined as the extent to which a patient takes medication as prescribed. ${ }^{8}$ Consequently, intensive interventions are essential to increase adherence and prevent relapse, and restore social functioning in order to improve the long-term prognosis. Long acting injectable (LAI) antipsychotics have been universally proposed 
as an effective tool for improving adherence, ${ }^{2,6}$ although the rate of use in the schizophrenia population remains low.

The present paper provides the readers with a comprehensive and up-to-date review of research reporting LAI effects on various outcome categories with the aim of increasing clinician awareness of a much underutilized tool in the treatment of schizophrenia. LAIs have been studied utilizing a wide range of methodologies (Table 1), such as retrospective, observational, open-label, and randomized controlled trials (RCTs). While an in-depth critique of research design is beyond the scope of this paper and can be found elsewhere, ${ }^{9}$ the topic of nonadherence presents unique methodological challenges that will be addressed. This paper begins with a review of studies on the overall effects of medication nonadherence in schizophrenia, and then outlines data on the impact of LAIs on more specific outcomes, such as clinical, quality of life (QoL), and economic. The last section before the conclusion discusses barriers, attitudes, and beliefs affecting the use of LAIs for treating schizophrenia.

\section{Impact of medication adherence on schizophrenia}

Medication nonadherence and treatment discontinuation are common occurrences in schizophrenia. The rate of medication discontinuation during the first year after a first episode of psychosis ranges from $26 \%$ to $44 \%,{ }^{10-12}$ while in the Clinical Antipsychotic Trials for Intervention Effectiveness (CATIE) trial the discontinuation rate was as high as $74 \% .{ }^{13}$ Poor adherence was reported in $59 \%$ of patients within the year after the first episode of psychosis. ${ }^{14}$ As many as two-thirds of patients are at least partially nonadherent to oral schizophrenia medication. ${ }^{6}$ These figures are also validated in large studies, such as a retrospective analysis of over 46,000 psychotic patients from a large insurance database, which found a high rate of antipsychotic medication discontinuation. ${ }^{15}$ Those who discontinued medication and then restarted therapy were more likely to discontinue again. Moreover, a population-based study of 6,662 patients found that one-third had discontinued antipsychotic therapy after 1 year, but even among the two-thirds who remained on therapy at 1 year, $20 \%$ were nonadherent. ${ }^{16}$

Nonadherence to antipsychotic medication represents not only an important clinical problem but also an economic burden in the treatment of schizophrenia, ${ }^{17-19}$ as it is associated with more frequent relapses, increased rates of hospital admission and rehospitalization, and persistence of psychotic symptoms. ${ }^{10}$ In contrast, treatment adherence may avoid rehospitalization and reduce relapses..$^{20}$
Table I Summary of references by topic and study description

\begin{tabular}{|c|c|c|}
\hline $\begin{array}{l}\text { Outcome } \\
\text { category }\end{array}$ & Study & Study description \\
\hline \multirow{11}{*}{$\begin{array}{l}\text { Medication } \\
\text { adherence }\end{array}$} & Lindenmayer et $\mathrm{al}^{8}$ & Randomized, double-blind \\
\hline & Morken et $\mathrm{al}^{10}$ & Open-label \\
\hline & Perkins et al" & Randomized, double-blind \\
\hline & Verdoux et al ${ }^{12}$ & Observational \\
\hline & Coldham et al $^{14}$ & Observational \\
\hline & Cooper et $\mathrm{al}^{16}$ & Population-based \\
\hline & Staring et $\mathrm{a}^{20}$ & Randomized \\
\hline & Novick et $\mathrm{al}^{21}$ & Observational \\
\hline & Ritchie et $\mathrm{al}^{22}$ & Open-label \\
\hline & Ascher-Svanum et $\mathrm{al}^{23}$ & Prospective, observational \\
\hline & McCabe et $\mathrm{al}^{70}$ & Observational \\
\hline \multirow[t]{16}{*}{ Clinical } & Crumlish et $\mathrm{al}^{4}$ & Prospective, longitudinal \\
\hline & Leucht et $\mathrm{al}^{5}$ & Meta-analysis \\
\hline & Robinson et $\mathrm{al}^{7}$ & Prospective, open-label \\
\hline & Lieberman et $\mathrm{al}^{13}$ & Randomized, double-blind \\
\hline & Tiihonen et $\mathrm{al}^{30}$ & Prospective cohort \\
\hline & Brnabic et $\mathrm{al}^{32}$ & Observational \\
\hline & Shi et $\mathrm{al}^{33}$ & Observational \\
\hline & Olivares et $\mathrm{a}^{27}$ & Longitudinal, observational \\
\hline & Zhu et $\mathrm{a}^{34}$ & Prospective, open-label \\
\hline & Rosenheck et $\mathrm{a}^{35}$ & Randomized, open-label \\
\hline & Haddad et $\mathrm{al}^{36}$ & Systematic review \\
\hline & Fusar-Poli et a $\left.\right|^{37}$ & Meta-analysis of RCTs \\
\hline & Kishimoto et a ${ }^{38}$ & Meta-analysis of RCTs \\
\hline & Andreasen et $\mathrm{al}^{42}$ & Longitudinal, observational \\
\hline & Kelin et $\mathrm{a}^{67}$ & Prospective, observational \\
\hline & Kelin et $\mathrm{a}^{68}$ & Prospective, observational \\
\hline Early treatment & Bartzokis et $\mathrm{a}^{40}$ & Randomized, open-label \\
\hline \multirow[t]{4}{*}{ with LAls } & Bartzokis $^{41}$ & Randomized, open-label \\
\hline & Andreasen et $\mathrm{al}^{42}$ & Longitudinal, observational \\
\hline & Taylor and $\mathrm{Ng}^{43}$ & Systematic review \\
\hline & Ascher-Svanum et a $\left.\right|^{44}$ & $\begin{array}{l}\text { Randomized, double-blind, } \\
\text { prospective cohort }\end{array}$ \\
\hline Health care & Olivares et $\mathrm{a}^{26}$ & Longitudinal, observational \\
\hline resource & Offord et $\mathrm{al}^{28}$ & Claims database \\
\hline \multirow[t]{6}{*}{ utilization } & Peng et $\mathrm{a}^{29}$ & Claims database \\
\hline & Ren et $\mathrm{a}^{3 \mid}$ & Open-label \\
\hline & Crivera et $\mathrm{al}^{45}$ & Observational \\
\hline & Taylor et $\mathrm{al}^{46}$ & Medical record review \\
\hline & Lin et $\mathrm{al}^{47}$ & Claims database \\
\hline & Bera et $\mathrm{a}^{48}$ & Claims database \\
\hline Impact on & Puschner et $\mathrm{a}^{69}$ & Randomized, open-label \\
\hline \multirow[t]{8}{*}{ quality of life } & Lloyd et $\mathrm{al}^{50}$ & Observational \\
\hline & De Marinis et $\mathrm{a}^{51}$ & Open-label \\
\hline & Macfadden et $\mathrm{al}^{52}$ & Longitudinal, observational \\
\hline & Witte et $\mathrm{al}^{53}$ & $\begin{array}{l}\text { Randomized, double-blind, } \\
\text { prospective cohort }\end{array}$ \\
\hline & Lambert et al ${ }^{54}$ & Open-label \\
\hline & Llorca et a $\left.\right|^{55}$ & Open-label \\
\hline & Furiak et $\mathrm{al}^{49}$ & Economic model \\
\hline & Osborne et $\mathrm{a}^{56}$ & Time trade-off study \\
\hline Attitudes and & Mohamed et $\mathrm{al}^{71}$ & Randomized, open-label \\
\hline perceptions & Dibonaventura et al ${ }^{72}$ & Nationwide survey \\
\hline \multirow[t]{3}{*}{ toward LAls } & Patel et $\mathrm{al}^{73}$ & Cross-sectional survey \\
\hline & Patel et a $\left.\right|^{57}$ & Survey \\
\hline & West et $\mathrm{a}^{58}$ & Survey \\
\hline
\end{tabular}

(Continued) 
Table I (Continued)

\begin{tabular}{lll}
\hline $\begin{array}{l}\text { Outcome } \\
\text { category }\end{array}$ & Study & Study description \\
\hline & Hamann et a ${ }^{59}$ & Survey \\
& Heres et al ${ }^{60}$ & Survey \\
& Jaeger and Rossler ${ }^{61}$ & Survey \\
& Heres et al ${ }^{62}$ & Survey \\
& Waddell and Taylor ${ }^{63}$ & Systematic review \\
& Heres et al ${ }^{64}$ & Survey \\
& Walburn et al ${ }^{65}$ & Systematic review \\
& Velligan et al ${ }^{81}$ & Systematic review \\
\hline
\end{tabular}

Abbreviations: RCTs, randomized controlled trials; LAls, long-acting injectables.

More specifically, many studies have reported poor outcomes associated with nonadherence to antipsychotics. Patients enrolled in a 3-year prospective trial of antipsychotic therapy were evaluated for predictors of adherence. ${ }^{21}$ Among over 6,700 patients followed for 3 years, $71 \%$ were adherent, and predictors of nonadherence were substance abuse and previous hospitalization. Nonadherence was associated with increased rates of relapse, hospitalization, and suicide. Morken et al studied 50 patients with schizophrenia or related disorders who were evaluated for the impact of adherence or nonadherence on psychotic symptoms, relapse, and hospital admission over a 24-month period. ${ }^{10}$ Nonadherence was associated with significant $(P<0.05)$ increases in relapse and hospitalization, and persistence of psychotic symptoms. The effect of nonadherence to antipsychotic medication was examined in an 8 -week study of patients with schizophrenia or schizoaffective disorder. ${ }^{8}$ Compared with patients who were adherent to medication, patients who had higher medication-discontinuation rates $(40.8 \%$ versus $[\mathrm{vs}] 24.5 \%, P<0.001)$ experienced less symptom improvement and lower response rates.

Adherence was evaluated in a geriatric population of schizophrenic patients who were followed for 3.5 years. ${ }^{22}$ Overall adherence was $66 \%$. Nonadherence was identified as an early event after initiating antipsychotic treatment, which suggests that patients who are adherent at 6 months are more likely to remain adherent. ${ }^{22}$ Ascher-Svanum et al examined the effect of adherence on outcomes in more than 1,900 schizophrenia patients over a 3-year period..$^{23}$ The overall adherence rate was $77 \%$. At 3 years, nonadherence was associated with an increased risk of hospitalization, greater use of psychiatric emergency services, and impaired mental functioning and satisfaction with life. Nonadherence to antipsychotic medication in the first year of the study was a predictor of poor outcomes later.

As will be outlined in the following sections, a significant body of research suggests that better medication adherence resulting from the use of LAIs improves outcomes.

\section{LAls and schizophrenia outcomes}

This section will review specific data from LAI studies evaluating relapse and hospitalization rates, use in early treatment, functional outcomes, utilization of health care resources, and QoL.

\section{Relapse and hospitalization rates}

Zhornitsky and Stip reviewed randomized and naturalistic studies comparing LAIs versus oral antipsychotic medications for treating schizophrenia to assess the efficacy and tolerability of LAIs. ${ }^{24}$ Overall, LAIs were associated with a lower rate of relapse versus oral antipsychotics, and the benefits of LAIs were greater in naturalistic studies.

The Electronic Schizophrenia Treatment Adherence Registry (e-STAR) is an international, multicenter, prospective, observational registry to assess the use of LAIs in patients with schizophrenia or schizoaffective disorder in a clinical practice setting. Discontinuation rates, hospitalization, functional outcomes, and costs of therapy are among the results reported from this study. ${ }^{25-27} \mathrm{~A}$ total of 1,659 patients completed the study. ${ }^{25}$ At 12 months after switching from oral to LAI antipsychotics, the percentage of patients who did not require hospitalization $(89.1 \%$ vs $67.0 \%)$ and did not relapse ( $85.4 \%$ vs $47.8 \%)$ was higher with LAIs than with oral antipsychotics. ${ }^{26}$ Cost-effectiveness per month per patient was lower for LAIs than for previous antipsychotic medication among patients who were defined as without hospitalization, without relapse, or without hospitalization and without relapse. At the 24-month follow-up, $81.8 \%$ of patients on LAIs versus $63.4 \%$ on oral antipsychotics had remained on therapy $(P<0.0001)$ and a significantly $(P=0.0165)$ greater reduction in Clinical Global Impression - Severity scores occurred with LAIs. ${ }^{27}$ Compared to the baseline period, those on LAIs had significantly $(P<0.05)$ greater reductions in the number and days of hospitalization. At 24 months, only $15 \%$ of patients had discontinued LAIs for insufficient response $(28.5 \%)$, patient/family choice $(26.1 \%)$, adverse events $(9.6 \%)$, and unacceptable tolerability $(6.0 \%){ }^{25}$ At 24 months, Global Assessment of Functioning scores improved significantly $(P<0.001)$ with LAIs versus baseline, and mean scores for those who discontinued LAIs were lower than for those who completed (55.4 vs 67.2). Compared to baseline, greater reduction in hospitalizations ( $66.2 \%$ reduction vs $29.2 \%$ ) and in the length ( $68 \%$ reduction vs $0 \%)$ and number ( 80.0 vs 14.3) of hospital stays were observed for those who completed therapy versus those who discontinued LAIs, and these differences remained at 24 months. 
Other studies have found similar beneficial results with the use of LAIs. Offord et al identified patients from a claims database with schizophrenia who initiated therapy with either LAI or oral antipsychotics. ${ }^{28}$ At the 12-month follow-up, those initiating LAI versus oral antipsychotics $(\mathrm{n}=2,610)$ had significant $(P<0.001)$ reductions versus baseline in the mean number of all-cause hospitalizations, schizophrenia-related hospitalizations, and length of hospital stay. Similarly, Peng et al examined schizophrenic patients in a large claims database for the impact of initiating LAIs on outcomes. ${ }^{29}$ After starting LAIs, the hospitalization rate declined from $49.7 \%$ to $22.4 \%(P<0.001)$, and the duration of hospitalization declined from 7.3 to 4.7 days. Total health care costs declined significantly $(P<0.05)$, mostly as a result of decreased hospitalization. Tiihonen et al evaluated the risk of rehospitalization and medication discontinuation from a database of patients hospitalized with a first episode of schizophrenia. ${ }^{30}$ Use of an LAI versus an oral antipsychotic was associated with a significantly $(P=0.007)$ lower risk of rehospitalization from relapse.

Ren et al studied patients who initiated LAIs in a Veterans Administration clinic for psychiatric outpatient visits and hospitalizations. ${ }^{31}$ Among 924 patients, the number of psychiatric-related outpatient visits increased from 24.6 to $39.1(P<0.001)$, the number of psychiatric hospitalizations decreased from 1.4 to $1.0(P<0.001)$, and the average inpatient length of stay was reduced from 20 to 14 days $(P<0.001)$. The proportion of patients who experienced at least one psychiatric-related hospitalization decreased from $68.9 \%$ to $45.7 \%(P<0.001)$, and the proportion with two hospitalizations decreased from $34.9 \%$ to $24.4 \%(P<0.001)$.

Patients who are nonadherent with oral antipsychotics are less likely to discontinue their medication for any cause when treatment is initiated with LAIs. ${ }^{32,33} \mathrm{~A}$ post hoc analysis from a 1-year prospective study from Brnabic et al evaluated outpatients with schizophrenia who were felt to be at risk for poor adherence with oral antipsychotics. ${ }^{32}$ Patients who were switched to LAI formulations were less likely to discontinue medication $(P=0.033)$ and discontinued later $(P=0.025)$ compared with patients on oral antipsychotics. Patients considered to be nonadherent on oral medication were less likely to discontinue LAIs for any reason.

Zhu et al assessed time to discontinuation for LAI versus oral antipsychotics in a 3-year prospective trial of schizophrenia patients. ${ }^{34}$ Patients on LAIs were at least twice as likely to remain on medication, and use of an LAI versus oral antipsychotic was associated with a longer time to discontinuation.
Despite the benefits from LAIs reported in most studies, some studies have failed to demonstrate outcome differences between LAIs and oral antipsychotics. For instance, in a prospective, randomized study, Rosenheck et al compared outcomes in 369 patients in the Veterans Affairs system with schizophrenia or schizoaffective disorder and at high risk for hospitalization after treatment with LAI or oral antipsychotics for 2 years. ${ }^{35}$ There was no difference in hospitalization rates, psychiatric symptoms, QoL, or global functioning between treatment groups. A systematic review by Haddad et al of first-generation LAIs found inconsistent evidence of benefits of LAI versus oral antipsychotics, although LAIs were associated with lower discontinuation rates. ${ }^{36} \mathrm{~A}$ recent meta-analysis of second-generation LAIs found no evidence of superiority of LAIs over oral antipsychotics. ${ }^{37} \mathrm{~A}$ modest benefit was observed for improvement in psychotic symptoms with LAIs versus placebo, but the benefits occurred with an increased incidence of extrapyramidal side effects. Kishimoto et al reported a meta-analysis of randomized controlled trials comparing LAIs with oral antipsychotics, and found that second-generation LAIs and oral drugs were similar for relapse prevention, discontinuation rate, hospitalization, and medication nonadherence. ${ }^{38}$ In contrast to nonrandomized studies that suggest LAI superiority over oral antipsychotic administration, RCTs have not consistently shown such difference. This discrepancy has been addressed by Kane et al ${ }^{39}$ and Kirson et al, ${ }^{9}$ who review the methodology utilized in LAI studies. For instance, while RCTs are considered the gold standard of research design, their application to the topic of adherence may present a methodological issue that could obscure the very question they are attempting to answer. This is because in strictly controlled research conditions, both comparison groups (oral vs LAI) tend to comply with the treatment regimen in ways that are better than real-world clinical practice. As a result, the increase in adherence by the group on oral antipsychotics under these research conditions could potentially be the reason why differences between oral and LAI regimens are minimized. In other words, the usually nonadherent group of patients on oral medication is underrepresented (patients are more adherent) due to laboratory settings. In order to resolve the discrepancy, Kane et al propose conducting further studies taking into account this potentially confounding variable. ${ }^{39}$

\section{Early treatment}

Treatment resistance and the deteriorating condition that develops in patients with chronic schizophrenia may occur because of a deficiency in intracortical myelination, which 
may be at least part of the underlying etiology of schizophrenia. ${ }^{40,41}$ Early in the treatment of schizophrenia, antipsychotic medication results in an initial increase in frontal lobe intracortical myelin volume, followed by a decrease in myelin volume during chronic disease. ${ }^{40}$ This pattern of intracortical myelin decline in chronic schizophrenia has been attributed to medication nonadherence, and perhaps could be altered with the use of LAIs. In a clinical study, intracortical myelination volume increased significantly $(P=0.005)$ with an LAI but not with oral antipsychotics in schizophrenic patients compared with healthy controls. ${ }^{40}$ Patients receiving LAIs had greater medication adherence and increases in intracortical myelination $(P<0.05)$ compared with healthy controls. These results suggest that LAIs may promote intracortical myelination and possibly a neuroprotective effect, as a result of better adherence to medication or variations in the pharmacokinetic profile of LAI versus oral antipsychotics. Findings from a recent study support the importance of treatment adherence and initiating therapy early after onset of illness. ${ }^{42}$ Patients with first-episode schizophrenia were evaluated with magnetic resonance imaging to determine the relationship between relapse and brain-tissue loss. The duration of relapse was related to significant decreases in total and regional (frontal) brain volumes over a 7-year follow-up period.

A systematic review was conducted of studies reporting the effects of LAIs for the early treatment of schizophrenia. ${ }^{43}$ From ten studies (cohort, randomized, or open) that met the criteria, LAIs were found to be effective for early schizophrenia. The authors concluded that LAIs improved symptom control and reduced the risk of relapse, especially when medication adherence was a concern or when the patient made the decision to use LAIs.

A recent double-blind, randomized trial evaluated whether early response ( $\geq 30 \%$ improvement by week 4 in Positive and Negative Syndrome Scale [PANSS]) to LAIs predicted subsequent response ( $\geq 40 \%$ improvement). ${ }^{44}$ Among 233 patients with schizophrenia, early response versus nonresponse predicted subsequent response to the LAIs, and early responders experienced significantly better clinical and functional outcomes $(P \leq 0.01)$. These findings suggest that there could be a very important role for LAIs in the treatment of early schizophrenia when traditionally these agents have been reserved for more advanced cases.

\section{Health care resource utilization}

An important consideration with any behavioral health therapy is the impact on medical resource utilization and health care costs. Crivera et al evaluated medical resource utilization in an observation study of 435 schizophrenia patients who were started on an LAI. ${ }^{45}$ At a 24-month follow-up, a significant $(P<0.001)$ decrease from baseline was observed in the number of hospitalizations and emergency room visits. Hospitalization for any reason decreased by $41 \%$, and for psychiatric reasons by $56 \%$; emergency room visits decreased by $40 \%$. In another study, medical records were reviewed to determine the impact of switching to LAIs on inpatient costs of care. ${ }^{46}$ In the 12 months after the LAI was initiated, 40 fewer hospitalizations were recorded compared to the 12-month period before LAI use. Lin et al assessed the impact of initiating treatment with LAIs or a broad range of oral antipsychotics on health care costs and adherence using a Medicare database. ${ }^{47}$ Although drug costs were significantly $(P<0.001)$ higher with LAI use, inpatient and outpatient health care costs were significantly $(P<0.001)$ lower with LAIs, while medication adherence was significantly higher $(P<0.001)$ with LAI versus oral antipsychotics. Research on schizophrenic subjects covered by Medicaid who initiated treatment with an LAI revealed significantly $(P<0.001)$ reduced overall and schizophrenia-related hospitalizations, length of stay, and hospital charges. ${ }^{48}$ After starting the LAI, annual total schizophrenia-related costs were reduced by $\$ 5,576$, and hospital costs were reduced by $\$ 7,744$. Data from a large, prospective interventional trial of over 2,000 schizophrenia patients found that good medication adherence was associated with lower utilization of health care services and increased utilization of group therapy. ${ }^{17}$ Psychiatric hospitalization rates were significantly $(P<0.001)$ lower among adherent patients.

The benefit of administering LAIs was determined in patients with schizophrenia using a model created to estimate the benefits of longer intervals between injections. ${ }^{49}$ Results of the model showed that administration every 3 months was less costly than monthly LAI and daily oral therapy. Extending the interval to 6 and 9 months further decreased the costs of therapy. The authors suggested that less frequent administration would be associated with better adherence and persistence and reduced opportunities to discontinue therapy.

\section{Quality of life}

QoL is an important parameter in assessing the overall benefit of a specific treatment, particularly for chronic conditions. Studies of patients switched from oral to LAI antipsychotics or those initiated on LAIs reported significant improvements 
in schizophrenia symptom control, QoL, satisfaction, and functioning. ${ }^{50-52}$ Following unsatisfactory treatment with oral antipsychotics, 182 schizophrenia patients were switched to LAIs for 6 months. ${ }^{50}$ Compared with baseline, significant $(P<0.05)$ improvement over 6 months was observed for the PANSS total and subscale scores. In addition, significant $(P<0.05)$ improvements in Global Assessment of Functioning, health-related QoL, and patient satisfaction were observed. The effects of LAIs on functional improvement and QoL were evaluated in an 8-week randomized, double-blind, placebo-controlled trial of 404 schizophrenic inpatients. ${ }^{53}$ Significant $(P<0.01)$ improvements with LAIs versus placebo were observed in QoL and Short Form (36) Health Survey total and subscale scores.

Macfadden et al evaluated the effectiveness of LAIs on QoL and functioning in a 24-month, prospective, observational study of 532 schizophrenia patients. ${ }^{52}$ After initiating therapy with LAIs, patients reported improvements at 3 months that persisted to the end of the 24-month follow-up. Improvements were observed in Global Assessment of Functioning, Strauss-Carpenter Levels of Functioning, Personal and Social Performance, and health status.

An analysis of clinical outcomes from the Switch To Risperidone Microspheres (StoRMi) trial was undertaken in schizophrenia patients who were switched from oral or first-generation LAIs to second-generation LAIs for lack of efficacy, side effects or noncompliance. ${ }^{51}$ After 6 months, improvements over baseline were observed with secondgeneration LAIs for symptoms, Global Assessment of Functioning, QoL, treatment satisfaction, and hospitalization rates. In a separate analysis from the StoRMi trial, symptomatic and functional improvements were evaluated in 529 patients with stable psychotic disorders who were switched from oral to LAI antipsychotics. ${ }^{54}$ After 18 months, $20 \%$ of patients experienced a combined improvement in symptoms, functional outcome, and QoL. Schizophrenia patients who were clinically stable on oral antipsychotics were switched for lack of efficacy, side effects, or noncompliance to LAIs for 6 months. ${ }^{55}$ The PANSS total and subscale scores improved significantly $(P<0.001)$ at 6 months. Compared with baseline, Global Assessment of Functioning, health-related QoL, and patient satisfaction also improved significantly.

Osborne et al determined the impact of 2-week, 4-week, and 3-month treatment intervals for an LAI. ${ }^{56}$ Improved QoL was observed with an increasing time interval between injections. The 2-week, 4-week, and 3-month intervals were significantly different from each other, with the highest
QoL scores observed with the 3-month interval between injections.

\section{Barriers to use of LAls in schizophrenia}

Utilization of LAIs by clinicians in the US is markedly lower than expected compared with other parts of the world, owing to a number of factors, including negative attitudes of health care professionals, treatment setting, and insurance coverage. ${ }^{6}$

A survey of physician attitudes toward the use of LAIs found that $50 \%$ had decreased their use over the past 5 years, despite acknowledging better adherence than with oral antipsychotics. ${ }^{57}$ Among the beliefs were that LAIs are less effective for first episodes of psychosis (38\%) and that patients always preferred oral antipsychotics (33\%). In another study, psychiatrists in the US were surveyed about nonadherence in patients with schizophrenia and their use of LAIs. ${ }^{58}$ These psychiatrists reported using LAIs in just 18\% of patients for nonadherence, but LAI use was more likely among psychiatrists who had a positive attitude about managing nonadherence. Another paper studied 106 psychiatrists to determine the incremental improvement in relapse prevention required for them to prescribe LAIs over oral antipsychotics. ${ }^{59}$ Most of these psychiatrists expected the LAI formulation to be superior to oral antipsychotics, but they also viewed LAIs as unpleasant for patients and failed to appreciate the impact of poor adherence on relapse rates. In another study, psychiatrists $(n=350)$ were surveyed about their reluctance to prescribe LAIs for schizophrenia or schizoaffective disorder. ${ }^{60}$ According to this study, physicians perceived that patient compliance with oral medication was adequate, and thus felt that use of an LAI was not necessary.

A survey of attitudes toward LAIs was conducted of patients, relatives, and psychiatrists. ${ }^{61}$ Compared with psychiatrists and relatives, patients expressed negative attitudes toward LAI formulations based on fear of loss of autonomy and concerns about pain on injection. Two-thirds of patients did not receive information about LAIs, and $<10 \%$ of psychiatrists used LAIs after a first psychotic episode. Another survey of 198 psychiatrists about their attitudes toward LAIs for first-episode psychosis revealed that limited availability of LAIs, rejection of this route of administration by the patient, and patient skepticism were the most important factors influencing decisions not to use LAIs. ${ }^{62}$

A systematic review of attitudes by patient and health care staff toward LAIs found positive attitudes among patients already on LAIs, and positive attitudes among staff that correlated with their knowledge of LAIs. ${ }^{63}$ Heres et al studied 
300 schizophrenic patients, and found that their acceptance of LAIs depended on previous experience with these drugs. ${ }^{64}$ Among those currently treated with LAIs, $73 \%$ were accepting of LAIs, while $23 \%$ of LAI-naive patients were accepting of LAIs. Walburn et al surveyed patients and nurses, and found that they generally had a positive attitude about the use of LAIs ${ }^{65}$ The authors identified the need for better-tolerated LAIs and improved education for both patients and health care professionals to encourage wider use. A systematic review of published literature was undertaken to identify the profile of an ideal patient candidate to receive LAIs. ${ }^{66}$ The authors concluded that a therapeutic alliance should be established between the health care professional and the patient when selecting treatment.

A naturalistic study described in two papers was conducted to determine the source of initial treatment decisions for patients with schizophrenia who were at risk for nonadherence, ${ }^{67}$ and also to evaluate causes for treatment discontinuation. ${ }^{68}$ Despite awareness of a risk for nonadherence, only $10.6 \%$ of patients were switched to LAIs. ${ }^{67}$ The LAI-switch group had a history of nonadherence (32.6\% vs $4.7 \%)$, recent substance abuse, poorer attitude toward medication $(P=0.004)$, and poorer awareness of their illness $(P=0.041)$. Over a 12 -month period, $24.4 \%$ of patients discontinued antipsychotic therapy..$^{70} \mathrm{~A}$ disconnect was identified between physician and patient assessment of adherence. Physicians felt that $55 \%$ of patients were at risk for an inadequate response due to nonadherence. In contrast, two-thirds of patients thought they were adherent with medication.

McCabe et al assessed the impact of the therapeutic relationship between patient and clinician on adherence to antipsychotic medication among patients with schizophrenia. ${ }^{70}$ It was found that a better relationship between patient and clinician was independently linked to improved medication adherence. The associations between patient insights into their disorder and attitudes toward medication and schizophrenia outcomes were also assessed in the CATIE trial cohort. ${ }^{71}$ Positive attitudes about antipsychotic medications were associated with significant decreases in psychopathology, improvement in community functioning, and greater medication adherence. ${ }^{71}$ Further, improved understanding by patients of their illness was as important as positive attitudes toward medication use in improving outcomes.

A cross-sectional survey of patients with schizophrenia found that side effects to antipsychotic drugs were highly prevalent, and medication nonadherence was significantly associated with the occurrence of these side effects. ${ }^{72}$ In addition, medication nonadherence was significantly associated with increased health care resource utilization. Another cross-sectional study on patient perspectives about antipsychotic medication was based on the presumption that the most important factor in nonadherence to medications was the presence of side effects. ${ }^{73}$ However, results from the study found that patient beliefs and attitudes about their disease and medication were more important for predicting self-reported adherence. ${ }^{73}$ Those with negative attitudes toward medication had lower rates of adherence. Further, prescribing an LAI as the sole intervention for nonadherence was not adequate; effective intervention required steps to modify negative attitudes.

As outlined, beliefs, perceptions, and attitudes about antipsychotic medications among both patients and health care professionals are other important contributing factors to poor adherence to prescribed medication. Efforts to improve or modify these factors may have an important impact on outcomes.

Furthermore, the studies reviewed in this section also highlight the need for better physician education on nonadherence, as research shows that clinicians greatly underestimate its presence.

\section{Summary and conclusion}

A need exists to produce antipsychotic agents that are effective, safe, well tolerated, and encourage long-term adherence, so that patients can experience the full benefits of treatment. While oral antipsychotics are effective for the treatment for schizophrenia, poor adherence remains a problem. Nonadherence results in increased rates of relapse and rehospitalization, poor response and recovery, and decreased function. Thus, other options should be considered to optimize adherence, improve symptomatic response, reduce relapse rates and hospitalization, and enhance functioning. LAIs represent a valuable option for treating schizophrenia given the known improvement in adherence, and yet these formulations are largely underutilized. Factors that may play a role in such underutilization include misperceptions by clinicians and patients about their efficacy and tolerability. While patients who have used LAIs have positive attitudes about their use, increased effort is needed to overcome the objections and negative attitudes of LAI-naive patients. Newer formulations of LAIs offer the potential to provide a lower rate of local injection-site reactions, a better pharmacokinetic profile, and increased ease of dosing. ${ }^{74}$ For their part, psychiatrists need to understand better the degree to which patients are nonadherent and emphasize the benefits of LAIs to the patient. Furthermore, underutilization of LAIs 
for schizophrenia continues, despite recommendations from clinical guidelines for their use as a treatment option when nonadherence is a concern, for frequent and recurrent relapse, or for patient preference. ${ }^{18,75-80}$ Outpatient LAI use may be further limited by the unavailability of personnel experienced in the administration of intramuscular formulations at most psychiatric office practices and community mental health centers. ${ }^{81}$ Increasing the use of LAIs will require education leading to the realization that the cost of having such personnel may be offset by reductions in hospital readmissions and overall better outcomes. This investment may find further support by changes in health care economics as the US and other countries shift from compensating the episodic care of the sick to rewarding those systems that dedicate resources to prevention and outcome improvement.

The significant body of evidence in recently published research reviewed in this paper suggests that LAIs offer an option for treatment that appears to improve adherence markedly, resulting in better outcomes for patients suffering from schizophrenia. Patients should be treated with antipsychotics earlier and for longer periods of time, and thus LAIs may be preferred because of better adherence. While methodological design controversy exists about the superiority of LAI versus oral antipsychotics, substantial data are available demonstrating the beneficial influence of adherence on schizophrenia outcomes. ${ }^{17-20,42,69}$ Short of obtaining blood levels, it is very difficult to assess adherence accurately in patients on oral medication. Rehospitalization is often the first sign of therapy abandonment, so there is little opportunity to review with the patient whatever the reasons for discontinuation are before relapse occurs. In contrast, a patient who misses administration of an LAI is without doubt nonadherent. Thus, at the most basic level, LAIs are extremely helpful in alerting the clinician to the precise moment when nonadherence begins. In such cases, the treating clinician can initiate efforts to restart therapy earlier and before much clinical worsening occurs. ${ }^{82}$ It is hoped that this review provides the clinician with substantial information regarding an already-available but underutilized treatment option that can have a significant impact on the outcome of schizophrenia.

\section{Acknowledgments}

The authors would like to acknowledge the editorial assistance of Richard S Perry, PharmD, in the preparation of this manuscript, which was supported by Alkermes, Inc., Waltham, MA, USA.

\section{Disclosure}

The authors report no conflicts of interest in this work.

\section{References}

1. Lieberman JA. Is schizophrenia a neurodegenerative disorder? A clinical and neurobiological perspective. Biol Psychiatry. 1999;46(6): 729-739.

2. Kane JM. Treatment strategies to prevent relapse and encourage remission. J Clin Psychiatry. 2007;68 Suppl 14:27-30.

3. Müller N. Mechanisms of relapse prevention in schizophrenia. Pharmacopsychiatry. 2004;37 Suppl 2:S141-S147.

4. Crumlish N, Whitty P, Clarke M, et al. Beyond the critical period: longitudinal study of 8-year outcome in first-episode non-affective psychosis. Br J Psychiatry. 2009;194(1):18-24.

5. Leucht S, Tardy M, Komossa K, et al. Antipsychotic drugs versus placebo for relapse prevention in schizophrenia: a systematic review and meta-analysis. Lancet. 2012;379(9831):2063-2071.

6. Patel MX, Taylor M, David AS. Antipsychotic long-acting injections: mind the gap. Br J Psychiatry Suppl. 2009;52:S1-S4.

7. Robinson D, Woerner MG, Alvir JM, et al. Predictors of relapse following response from a first episode of schizophrenia or schizoaffective disorder. Arch Gen Psychiatry. 1999;56(3): 241-247.

8. Lindenmayer JP, Liu-Seifert H, Kulkarni PM, et al. Medication nonadherence and treatment outcome in patients with schizophrenia or schizoaffective disorder with suboptimal prior response. J Clin Psychiatry. 2009;70(7):990-996.

9. Kirson NY, Weiden PJ, Yermakov S, et al. Efficacy and effectiveness of depot versus oral antipsychotics in schizophrenia: synthesizing results across different research designs. J Clin Psychiatry. 2013;74(6): 568-575.

10. Morken G, Widen JH, Grawe RW. Non-adherence to antipsychotic medication, relapse and rehospitalisation in recent-onset schizophrenia. BMC Psychiatry. 2008; $8: 32$.

11. Perkins DO, Gu H, Weiden PJ, McEvoy JP, Hamer RM, Lieberman JA. Predictors of treatment discontinuation and medication nonadherence in patients recovering from a first episode of schizophrenia, schizophreniform disorder, or schizoaffective disorder: a randomized, double-blind, flexible-dose, multicenter study. J Clin Psychiatry. 2008;69(1):106-113.

12. Verdoux H, Lengronne J, Liraud F, et al. Medication adherence in psychosis: predictors and impact on outcome. A 2-year follow-up of first-admitted subjects. Acta Psychiatr Scand. 2000;102(3): 203-210.

13. Lieberman JA, Stroup TS, McEvoy JP, et al. Effectiveness of antipsychotic drugs in patients with chronic schizophrenia. $N$ Engl J Med. 2005;353(12):1209-1223.

14. Coldham EL, Addington J, Addington D. Medication adherence of individuals with a first episode of psychosis. Acta Psychiatr Scand. 2002;106(4):286-290.

15. Moisan J, Grégoire JP. Patterns of discontinuation of atypical antipsychotics in the province of Québec: a retrospective prescription claims database analysis. Clin Ther. 2010;32 Suppl 1:S21-S31.

16. Cooper D, Moisan J, Grégoire JP. Adherence to atypical antipsychotic treatment among newly treated patients: a population-based study in schizophrenia. J Clin Psychiatry. 2007;68(6):818-825.

17. Ascher-Svanum H, Zhu B, Faries DE, Furiak NM, Montgomery W. Medication adherence levels and differential use of mental-health services in the treatment of schizophrenia. BMC Res Notes. 2009;2:6.

18. Barnes TR. Evidence-based guidelines for the pharmacological treatment of schizophrenia: recommendations from the British Association for Psychopharmacology. J Psychopharmacol. 2011;25(5):567-620. 
19. Hasan A, Falkai P, Wobrock T, et al. World Federation of Societies of Biological Psychiatry (WFSBP) Guidelines for Biological Treatment of Schizophrenia, part 1: update 2012 on the acute treatment of schizophrenia and the management of treatment resistance. World J Biol Psychiatry. 2012;13(5):318-378.

20. Staring AB, Van der Gaag M, Koopmans GT, et al. Treatment adherence therapy in people with psychotic disorders: randomised controlled trial. Br J Psychiatry. 2010;197(6):448-455.

21. Novick D, Haro JM, Suarez D, Perez V, Dittmann RW, Haddad PM. Predictors and clinical consequences of non-adherence with antipsychotic medication in the outpatient treatment of schizophrenia. Psychiatry Res. 2010;176(203):109-113.

22. Ritchie CW, Harrigan S, Mastwyk M, Macfarlane S, Cheesman N, Ames D. Predictors of adherence to atypical antipsychotics (risperidone or olanzapine) in older patients with schizophrenia: an open study of 3(1/2) years duration. Int J Geriatr Psychiatry. 2010;25(4):411-418.

23. Ascher-Svanum H, Faries DE, Zhu B, Ernst FR, Swartz MS, Swanson JW. Medication adherence and long-term functional outcomes in the treatment of schizophrenia in usual care. J Clin Psychiatry. 2006;67(3): 453-460.

24. Zhornitsky S, Stip E. Oral versus long-acting injectable antipsychotics in the treatment of schizophrenia and special populations at risk for treatment nonadherence: a systematic review. Schizophr Res Treatment. 2012;2012:407171.

25. Peuskens J, Olivares JM, Pecenak J, et al. Treatment retention with risperidone long-acting injection: 24-month results from the Electronic Schizophrenia Treatment Adherence Registry (e-STAR) in six countries. Curr Med Res Opin. 2010;26(3):501-509.

26. Olivares JM, Rodriguez-Martinez A, Burón JA, Alonso-Escolano D, Rodriguez-Morales A. Cost-effectiveness analysis of switching antipsychotic medication to long-acting injectable risperidone in patients with schizophrenia: a 12- and 24-month follow-up from the e-STAR database in Spain. Appl Health Econ Health Policy. 2008;6(1): 41-53.

27. Olivares JM, Rodriguez-Morales A, Diels J, Povey M, Jacobs A, Zhao Z. Long-term outcomes in patients with schizophrenia treated with risperidone long-acting injection or oral antipsychotics in Spain: results from the electronic Schizophrenia Treatment Adherence Registry (e-STAR). Eur Psychiatry. 2009;24(5):287-296.

28. Offord S, Wong B, Mirski D, Baker RA, Lin J. Healthcare resource usage of schizophrenia patients initiating long-acting injectable antipsychotics vs oral. J Med Econ. 2013;16(2):231-239.

29. Peng X, Ascher-Svanum H, Faries D, Conley RR, Schuh KJ. Decline in hospitalization risk and health care cost after initiation of depot antipsychotics in the treatment of schizophrenia. Clinicoecon Outcomes Res. 2011;3:9-14.

30. Tiihonen J, Haukka J, Taylor M, Haddad PM, Patel MX, Korhonen P. A nationwide cohort study of oral and depot antipsychotics after first hospitalization for schizophrenia. Am J Psychiatry. 2011;168(6): 603-609.

31. Ren XS, Crivera C, Sikirica M, Dirani R, Qian S, Kazis LE. Evaluation of health services use following the initiation of risperidone longacting therapy among schizophrenia patients in the Veterans Health Administration. J Clin Pharm Ther. 2011;36(3):383-389.

32. Brnabic AJ, Kelin K, Ascher-Svanum H, Montgomery W, Kadziola Z, Karagianis J. Medication discontinuation with depot and oral antipsychotics in outpatients with schizophrenia: comparison of matched cohorts from a 12-month observational study. Int J Clin Pract 2011;65(9):945-953.

33. Shi L, Ascher-Svanum H, Zhu B, Faries D, Montgomery W, Marder SR Characteristics and use patterns of patients taking first-generation depot antipsychotics or oral antipsychotics for schizophrenia. Psychiatr Serv. 2007;58(4):482-488.

34. Zhu B, Ascher-Svanum H, Shi L, Faries D, Montgomery W, Marder SR. Time to discontinuation of depot and oral first-generation antipsychotics in the usual care of schizophrenia. Psychiatr Serv. 2008;59(3): 315-317.
35. Rosenheck RA, Krystal JH, Lew R, et al. Long-acting risperidone and oral antipsychotics in unstable schizophrenia. $N$ Engl J Med. 2011;364(9):842-851.

36. Haddad PM, Taylor M, Niaz OS. First-generation antipsychotic longacting injections $\mathrm{v}$ oral antipsychotics in schizophrenia: systematic review of randomised controlled trials and observational studies. $\mathrm{Br} J$ Psychiatry Suppl. 2009;52:S20-S28.

37. Fusar-Poli P, Kempton MJ, Rosenheck RA. Efficacy and safety of second-generation long-acting injections in schizophrenia: a metaanalysis of randomized-controlled trials. Int Clin Psychopharmacol. 2013;28(2):57-66.

38. Kishimoto T, Robenzadeh A, Leucht C, et al. Long-acting injectable vs oral antipsychotics for relapse prevention in schizophrenia: a metaanalysis of randomized trials. Schizophr Bull. Epub January 2, 2013.

39. Kane JM, Kishimoto T, Correll CU. Assessing the comparative effectiveness of long-acting injectable vs oral antipsychotic medications in the prevention of relapse provides a case study in comparative effectiveness research in psychiatry. J Clin Epidemiol. 2013;66(Suppl 8): S37-S41.

40. Bartzokis G, Lu PH, Raven EP, et al. Impact on intracortical myelination trajectory of long acting injection versus oral risperidone in first-episode schizophrenia. Schizophr Res. 2012;140(1-3):122-128.

41. Bartzokis G. Schizophrenia: breakdown in the well-regulated lifelong process of brain development and maturation. Neuropsychopharmacology. 2002;27(4):672-683.

42. Andreasen NC, Liu D, Ziebell S, Vora A, Ho BC. Relapse duration, treatment intensity, and brain tissue loss in schizophrenia: a prospective longitudinal MRI study. Am J Psychiatry. 2013;170(6):609-615.

43. Taylor M, Ng KY. Should long-acting (depot) antipsychotics be used in early schizophrenia? A systematic review. Aust $N$ Z J Psychiatry. 2013;47(7):624-630.

44. Ascher-Svanum H, Zhao F, Detke HC, et al. Early response predicts subsequent response to olanzapine long-acting injection in a randomized, double-blind clinical trial of treatment for schizophrenia. $B M C$ Psychiatry. 2011;11:152.

45. Crivera C, DeSouza C, Kozma CM, Dirani RD, Mao L, Macfadden W. Resource utilization in patients with schizophrenia who initiated risperidone long-acting therapy: results from the Schizophrenia Outcomes Utilization Relapse and Clinical Evaluation (SOURCE). BMC Psychiatry. 2011;11:168.

46. Taylor M, Currie A, Lloyd K, Price M, Peperell K. Impact of risperidone long acting injection on resource utilization in psychiatric secondary care. J Psychopharmacol. 2008;22(2):128-131.

47. Lin J, Wong B, Offord S, Mirski D. Healthcare cost reductions associated with the use of LAI formulations of antipsychotic medications versus oral among patients with schizophrenia. J Behav Health Serv Res. 2013;40(3):355-366.

48. Bera R, Offord S, Zubek D, et al. Impact on healthcare resource usage and costs among Medicaid-insured schizophrenia patients after initiation of treatment with long-acting injectable antipsychotics. J Med Econ. 2013;16(4):522-528.

49. Furiak NM, Gahn JC, Klein RW, Camper SB, Summers KH. Estimated economic benefits from low-frequency administration of atypical antipsychotics in treatment of schizophrenia: a decision model. Ann Gen Psychiatry. 2012;11(1):29.

50. Lloyd K, Latif MA, Simpson S, Shrestha KL. Switching stable patients with schizophrenia from depot and oral antipsychotics to long-acting injectable risperidone: efficacy, quality of life and functional outcome. Hum Psychopharmacol. 2010;25(3):243-252.

51. De Marinis T, Saleem PT, Glue P, et al. Switching to long-acting injectable risperidone is beneficial with regard to clinical outcomes, regardless of previous conventional medication in patients with schizophrenia. Pharmacopsychiatry. 2007;40(6):257-263.

52. Macfadden W, DeSouza C, Crivera C, et al. Assessment of effectiveness measures in patients with schizophrenia initiated on risperidone long-acting therapy: the SOURCE study results. BMC Psychiatry. 2011;11:167. 
53. Witte MM, Case MG, Schuh KJ, Ascher-Svanum H. Effects of olanzapine long-acting injection on levels of functioning among acutely ill patients with schizophrenia. Curr Med Res Opin. 2012;28(3): 315-323.

54. Lambert M, De Marinis T, Pfeil J, Naber D, Schreiner A. Establishing remission and good clinical functioning in schizophrenia: predictors of best outcome with long-term risperidone long-acting injectable treatment. Eur Psychiatry. 2010;25(4):220-229.

55. Llorca PM, Bouhours P, Moreau-Mallet V. Improved symptom control, functioning and satisfaction in French patients treated with long-acting injectable risperidone. Encephale. 2008;34(2):170-178.

56. Osborne RH, Dalton A, Hertel J, Schrover R, Smith DK. Healthrelated quality of life advantage of long-acting injectable antipsychotic treatment for schizophrenia: a time trade-off study. Health Qual Life Outcomes. 2012;10:35.

57. Patel MX, Haddad PM, Chaudhry IB, McLoughlin S, Husain N, DavidAS. Psychiatrists' use, knowledge and attitudes to first- and secondgeneration antipsychotic long-acting injections: comparisons over 5 years. J Psychopharmacol. 2010;24(10):1473-1482.

58. West JC, Marcus SC, Wilk J, Countis LM, Regier DA, Olfson M. Use of depot antipsychotic medications for medication nonadherence in schizophrenia. Schizophr Bull. 2008;34(5):995-1001.

59. Hamann J, Mendel R, Heres S, Leucht S, Kissling W. How much more effective do depot antipsychotics have to be compared to oral antipsychotics before they are prescribed? Eur Neuropsychopharmacol. 2010;20(4):276-279.

60. Heres S, Hamann J, Kissling W, Leucht S. Attitudes of psychiatrists toward antipsychotic depot medication. J Clin Psychiatry. 2006;67(12): 1948-1953.

61. Jaeger M, Rossler W. Attitudes towards long-acting depot antipsychotics: a survey of patients, relatives and psychiatrists. Psychiatry Res. 2010;175(1-2):58-62.

62. Heres S, Reichhart T, Hamann J, Mendel R, Leucht S, Kissling W. Psychiatrists' attitude to antipsychotic depot treatment in patients with first-episode schizophrenia. Eur Psychiatry. 2011;26(5):297-301.

63. Waddell L, Taylor M. Attitudes of patients and mental health staff to antipsychotic long-acting injections: systematic review. Br J Psychiatry Suppl. 2009;52:S43-S50.

64. Heres S, Schmitz FS, Leucht S, Pajonk FG. The attitude of patients towards antipsychotic depot treatment. Int Clin Psychopharmacol. 2007;22(5):275-282.

65. Walburn J, Gray R, Gournay K, Quraishi S, David AS. Systematic review of patient and nurse attitudes to depot antipsychotic medication. $\mathrm{Br} \mathrm{J}$ Psychiatry. 2001;179:300-307.

66. Rossi G, Frediani S, Rossi R, Rossi A. Long-acting antipsychotic drugs for the treatment of schizophrenia: use in daily practice from naturalistic observations. BMC Psychiatry. 2012;12:122.

67. Kelin K, Brnabic AJ, Newton R, et al. Baseline characteristics and initial treatment decisions for patients with schizophrenia at risk of treatment nonadherence. Patient Prefer Adherence. 2010;4:301-311.
68. Kelin K, Lambert T Jr, Brnabic AJ, et al. Treatment discontinuation and clinical outcomes in the 1-year naturalistic treatment of patients with schizophrenia at risk of treatment nonadherence. Patient Prefer Adherence. 2011;5:213-222.

69. Puschner B, Angermeyer MC, Leese M, et al. Course of adherence to medication and quality of life in people with schizophrenia. Psychiatry Res. 2009;165(3):224-233.

70. McCabe R, Bullenkamp J, Hansson L, et al. The therapeutic relationship and adherence to antipsychotic medication in schizophrenia. PLoS One. 2012;7(4): 36080.

71. Mohamed S, Rosenheck R, McEvoy J, Swartz M, Stroup S, Lieberman JA. Cross-sectional and longitudinal relationships between insight and attitudes toward medication and clinical outcomes in chronic schizophrenia. Schizophr Bull. 2009;35(2):336-346.

72. Dibonaventura M, Gabriel S, Dupclay L, Gupta S, Kim E. A patient perspective of the impact of medication side effects on adherence: results of a cross-sectional nationwide survey of patients with schizophrenia. BMC Psychiatry. 2012;12:20.

73. Patel MX, de Zoysa N, Bernadt M, David AS. A cross-sectional study of patients' perspectives on adherence to antipsychotic medication: depot versus oral. J Clin Psychiatry. 2008;69(10):1548-1556.

74. Lambert TJ. Practical management of schizophrenia: the role of longacting antipsychotics. Int Clin Psychopharmacol. Epub June 4, 2013.

75. Kane JM, Garcia-Ribera C. Clinical guideline recommendations for antipsychotic long-acting injections. Br J Psychiatry Suppl. 2009;52:S63-S67.

76. Buchanan RW, Kreyenbuhl J, Kelly DL, et al. The 2009 schizophrenia PORT psychopharmacological treatment recommendations and summary statements. Schizophr Bull. 2010;36(1):71-93.

77. Kreyenbuhl J, Buchanan RW, Dickerson FB, Dixon LB. The Schizophrenia Patient Outcomes Research Team (PORT): updated treatment recommendations 2009. Schizophr Bull. 2010;36(1):94-103.

78. Canadian Psychiatric Association. Clinical practice guidelines. Treatment of schizophrenia. Can J Psychiatry. 2005;50(13 Suppl 1): 7S-57S.

79. Falkai P, Wobrock T, Lieberman J, Glenthoj B, Gattaz WF, Möller HJ. World Federation of Societies of Biological Psychiatry (WFSBP) guidelines for biological treatment of schizophrenia, part 2: long-term treatment of schizophrenia. World J Biol Psychiatry. 2006;7(1):5-40.

80. Lehman AF, Lieberman JA, Dixon LB, et al. Practice guideline for the treatment of patients with schizophrenia, second edition. Am J Psychiatry. 2004;161(Suppl 2):1-56.

81. Velligan DI, Medellin E, Draper M, et al. Barriers to, and strategies for, starting a long acting injection clinic in a community mental health center. Community Ment Health J. 2011;47(6):654-659.

82. Nasrallah HA. The case for long-acting antipsychotic agents in the post-CATIE era. Acta Psychiatr Scand. 2007;115(4):260-267.
Patient Preference and Adherence

\section{Publish your work in this journal}

Patient Preference and Adherence is an international, peer-reviewed, open access journal focusing on the growing importance of patient preference and adherence throughout the therapeutic continuum. Patient satisfaction, acceptability, quality of life, compliance, persistence and their role in developing new therapeutic modalities and compounds to

\section{Dovepress}

optimize clinical outcomes for existing disease states are major areas of interest. This journal has been accepted for indexing on PubMed Central. The manuscript management system is completely online and includes a very quick and fair peer-review system. Visit http://www.dovepress.com/ testimonials.php to read real quotes from published authors. 